\title{
EVALUATION OF DAMAGE IN REINFORCED CONCRETE COLUMNS UNDER BIAXIAL LOADING
}

\author{
Hugo Rodrigues $^{1,2^{*}}$, António Arêde ${ }^{3}$, Humberto Varum ${ }^{1}$, Aníbal Costa ${ }^{1}$ \\ ${ }^{1}$ Civil Engineering Department, University of Aveiro, Portugal \\ hrodrigues@ua.pt, hvarum@ua.pt, agc@ua.pt \\ ${ }^{2}$ Faculty of Natural Sciences, Engineering and Technology \\ Oporto Lusophone University \\ ${ }^{3}$ Civil Engineering Department, Faculty of Engineering, University of Porto \\ aarede@fe.up.pt
}

Keywords: Column, Experimental study, Biaxial bending, Damage, Damage index.

\begin{abstract}
The present study is focused on the analysis of damage evolution observed in an experimental campaign on 24 RC columns tested under uniaxial and biaxial loading. The observed damage evolution and damage states are compared for uniaxial and biaxial loading conditions. The test results show that for biaxial loading conditions each damage limit state occurs for lower drift demands when compared with the corresponding test for uniaxial demand (a reduction of 50-75\% was found). The deformation demand associated with each damage state is compared with performance objectives proposed in international guidelines. Finally, and based on the philosophy of the Park \& Ang uniaxial damage index, two new expressions are proposed for the evaluation of damage in $R C$ elements under biaxial loading. These expressions are calibrated against the experimental results obtained with the tests on columns based on a scoring process to choose the best DI estimator.
\end{abstract}




\section{INTRODUCTION}

The response of reinforced concrete (RC) members loaded by biaxial bending moment reversals with constant or variable axial force is recognized as an important research topic for building structures in earthquake prone regions. This is justified by, at least, the two following major reasons: i) the actual behavior of RC building columns under earthquake actions is strongly related to the random characteristics of the seismic event, the building's threedimensional (3D) response characteristics and structural irregularities; ii) the biaxial bending moment cyclic demands applied to a given RC column tend to reduce its capacity and to foster the stiffness and strength deterioration process during successive load reversals $[1,2]$.

However, experimental research work on the inelastic response of $\mathrm{RC}$ members under compression axial force and biaxial lateral cyclic bending loading conditions is currently very limited, which may be justified by the uncertainties concerning the relation and combination of the two orthogonal horizontal load paths, as well as the complexity of the experimental setup required to perform appropriate tests. Consequently, current knowledge on the inelastic response of RC columns under biaxial cyclic moments is still very much behind the present understanding of the 1D cyclic bending behavior with compressive axial load [1, 3-5].

In general, most research findings agree that, besides the expected significant influence of axial loads on the hysteretic response of columns, the 2D transversal load cycles are responsible for increasing the stiffness and strength degradation, when compared to the 1D response. In addition, the failure mechanism of RC columns is found to be highly dependent of the load path, which greatly affects both the ductility and energy dissipation capacity of the columns. On the other hand, there is some experimental evidence that plastic hinge lengths tend to be stable at around their theoretical values and are not greatly affected by 2D loading [1].

The present study is focused on the analysis of damage evolution observed in an experimental campaign on $24 \mathrm{RC}$ columns tested under uniaxial and biaxial loading. The observed damage states are compared for uniaxial and biaxial loading conditions. The deformation demand associated with each damage state is compared with proposed performance objectives in international guidelines (FEMA 356 [6] and VISION 2000 [7]). Finally, analytical expressions based on the Park \& Ang damage index $[8,9]$ are proposed and their accuracy in estimating damage is tested by a comparison with the observed experimental results.

\section{EXPERIMENTAL CAMPAIGN}

An experimental campaign was carried out on $24 \mathrm{RC}$ columns, tested under uniaxial and biaxial cyclic loading. The specimens consisted of RC columns built as a cantilever cast in a heavily reinforced foundation. The columns were subjected to a constant axial load and cyclic lateral actions under displacement controlled conditions. The general characteristics of the specimens and testing conditions are summarized in Figure 1 and Table 1.

For each column specimen test, the following general designation "PB\$-N\#\#" was adopted, where:

- $\$ \$$ takes the value "01" for uniaxial test on the strong direction (X direction), the value " 02 " for uniaxial tests on the weak direction (Y direction) and the value "12" for biaxial tests;

- \#\# represents the reference number of the column specimen.

A more detailed description of the columns' geometry, material properties, reinforcement details and test results is reported in [10]. The materials used in the specimen design phase were regular concrete, (see compressive strength in Table 1). These values are below than the expected ones for to the ordered concrete, but this fact was duly taken into account in the re- 
sult analysis so as to not affect the main objectives of the present study. The reinforcement presents a mean yielding strength of $450 \mathrm{MPa}$ and ultimate strength around $477 \mathrm{MPa}$.

In order to characterize the response of the column specimens, cyclic lateral displacements were imposed at the top of the column with steadily increasing demand levels. For the biaxial tests four different patterns for the demands history were considered, namely one in which the displacement cycles are applied alternately in the two horizontal directions (cruciform path), one with an expanding rhombus shape, one expanding square centred in the origin and finally a circular load path.
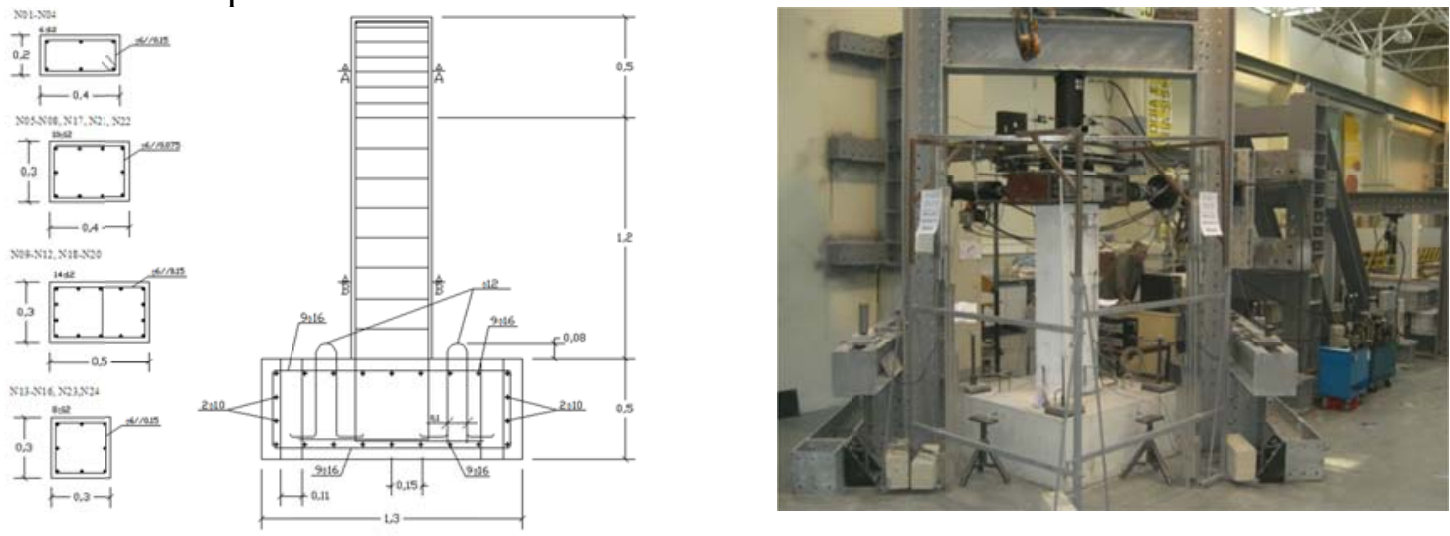

Figure 1 - Testing setup: a) RC column specimen dimensions and reinforcement detailing; b) General view of the testing set-up

Three cycles were repeated for each lateral deformation demand level. This procedure allows for the understanding of the column's behaviour and a comparison between different tests. It provides information for the development and calibration of numerical models; in this case, the following nominal peak displacement levels were considered in the directions of loading ( $\mathrm{x}$ and $\mathrm{y}$ ) - (displacement in $\mathrm{mm}$, and corresponding drift in percentage): 3, 5, 10, 4, $12,15,7,20,25,30,35,40,45,50,55,60,65,70,75,80[10,11]$. For all the tests, the first branch of the load path is imposed in the direction (X) of the column.

Due to the large number of tests, only an example of the global results are presented in terms of shear-drift curves (along the $\mathrm{X}$ and $\mathrm{Y}$ axes) in Figure 2, but analysis of the results for the complete testing program [10] yields these main findings:

- For columns tested with the same axial load ratio, the initial column stiffness in each directions was not significantly affected by the biaxial load path;

- As expected in the uniaxial tests, the shear-drift curves showed four main branches, corresponding to pre-cracking response, post-cracking until the reinforcing steel yields, a plateau or post-yield hardening zone, and a softening phase. However, in the biaxial tests the plateau tended to be shorter and the softening was more pronounced, i.e., a more abrupt decay of the column strength was observed with increasing lateral deformation demands;

- As expected, the maximum strength values in one specific direction of the columns were lower for all biaxial tests compared with those for the corresponding uniaxial tests. Biaxial loading induced a $20-30 \%$ reduction in the maximum strength of the columns in their weak direction, $\mathrm{Y}$, and an $8-15 \%$ reduction in the stronger direction, $\mathrm{X}$;

- The ultimate ductility was significantly reduced in columns subjected to biaxial load paths; 
- The strength degradation was practically zero in the first loading cycles, increasing after displacement ductility demands of about 3 . From the strength degradation analysis, more pronounced strength degradation was observed for biaxial tests when compared with the corresponding uniaxial tests.

- It was observed that the equivalent global damping for columns tested biaxially is clearly dependent on the load path. Comparing the results obtained for uniaxial and biaxial load paths, the cruciform and rhombus paths present similar equivalent global damping. However, the quadrangular and circular paths present higher levels of damping when compared to that obtained for similar demands in the uniaxial tests. For example, for ductility factor of 6 in the columns tested under uniaxial load conditions an equivalent damping of around $20 \%$ was reached, while for the quadrangular load path it was reached an equivalent damping of approximately $30 \%$ [5].

Table 1 - Specimen specifications and loading characteristics

\begin{tabular}{|c|c|c|c|c|c|c|}
\hline Series & Column & $\begin{array}{c}\text { Cross-Section } \\
\text { Dimensions } \\
{[\mathrm{cm} \mathrm{x} \mathrm{cm]}}\end{array}$ & $\begin{array}{c}\mathrm{f}_{\mathrm{cm}} \\
{[\mathrm{MPa}]}\end{array}$ & $\begin{array}{c}\mathrm{N} \\
{[\mathrm{kN}]}\end{array}$ & $\begin{array}{c}v \\
\mathrm{~N} /\left(\mathrm{A}_{\mathrm{c}} \cdot \mathrm{f}_{\mathrm{cm}}\right)\end{array}$ & $\begin{array}{c}\text { Displacement } \\
\text { path type }\end{array}$ \\
\hline 1 & $\begin{array}{l}\text { PB01-N01 } \\
\text { PB02-N02 } \\
\text { PB12-N03 } \\
\text { PB12-N04 }\end{array}$ & $20 \times 40$ & 48.35 & 170 & 0.04 & $\begin{array}{c}\text { Uniaxial Strong } \\
\text { Uniaxial Weak } \\
\text { Cruciform } \\
\text { Rhombus }\end{array}$ \\
\hline 2 & $\begin{array}{l}\text { PB01-N05 } \\
\text { PB02-N06 } \\
\text { PB12-N07 } \\
\text { PB12-N08 } \\
\text { PB12-N17 }\end{array}$ & $30 \times 40$ & 36.30 & 510 & 0.12 & $\begin{array}{c}\text { Uniaxial Strong } \\
\text { Uniaxial Weak } \\
\text { Rhombus } \\
\text { Quadrangular } \\
\text { Circular }\end{array}$ \\
\hline 3 & $\begin{array}{l}\text { PB01-N09 } \\
\text { PB02-N10 } \\
\text { PB12-N11 } \\
\text { PB12-N12 } \\
\text { PB12-N18 }\end{array}$ & $30 \times 50$ & 36.30 & 440 & 0.08 & $\begin{array}{c}\text { Uniaxial Strong } \\
\text { Uniaxial Weak } \\
\text { Rhombus } \\
\text { Quadrangular } \\
\text { Circular }\end{array}$ \\
\hline 4 & $\begin{array}{l}\text { PB01-N13 } \\
\text { PB12-N14 } \\
\text { PB12-N15 } \\
\text { PB12-N16 }\end{array}$ & $30 \times 30$ & 21.57 & 210 & 0.1 & $\begin{array}{c}\text { Uniaxial } \\
\text { Rhombus } \\
\text { Quadrangular } \\
\text { Circular }\end{array}$ \\
\hline 5 & $\begin{array}{l}\text { PB12-N19 } \\
\text { PB12-N20 }\end{array}$ & $30 \times 50$ & 43.14 & $\begin{array}{l}300 \\
600\end{array}$ & $\begin{array}{c}0.045 \\
0.09\end{array}$ & $\begin{array}{l}\text { Rhombus } \\
\text { Rhombus }\end{array}$ \\
\hline 6 & $\begin{array}{l}\text { PB12-N21 } \\
\text { PB12-N22 }\end{array}$ & $30 \times 40$ & 43.14 & 620 & 0.12 & $\begin{array}{c}\text { Rhombus } \\
\text { Quadrangular }\end{array}$ \\
\hline 7 & $\begin{array}{l}\text { PB12-N23 } \\
\text { PB12-N24 }\end{array}$ & $30 \times 30$ & 36.30 & 650 & 0.2 & $\begin{array}{c}\text { Rhombus } \\
\text { Quadrangular }\end{array}$ \\
\hline
\end{tabular}



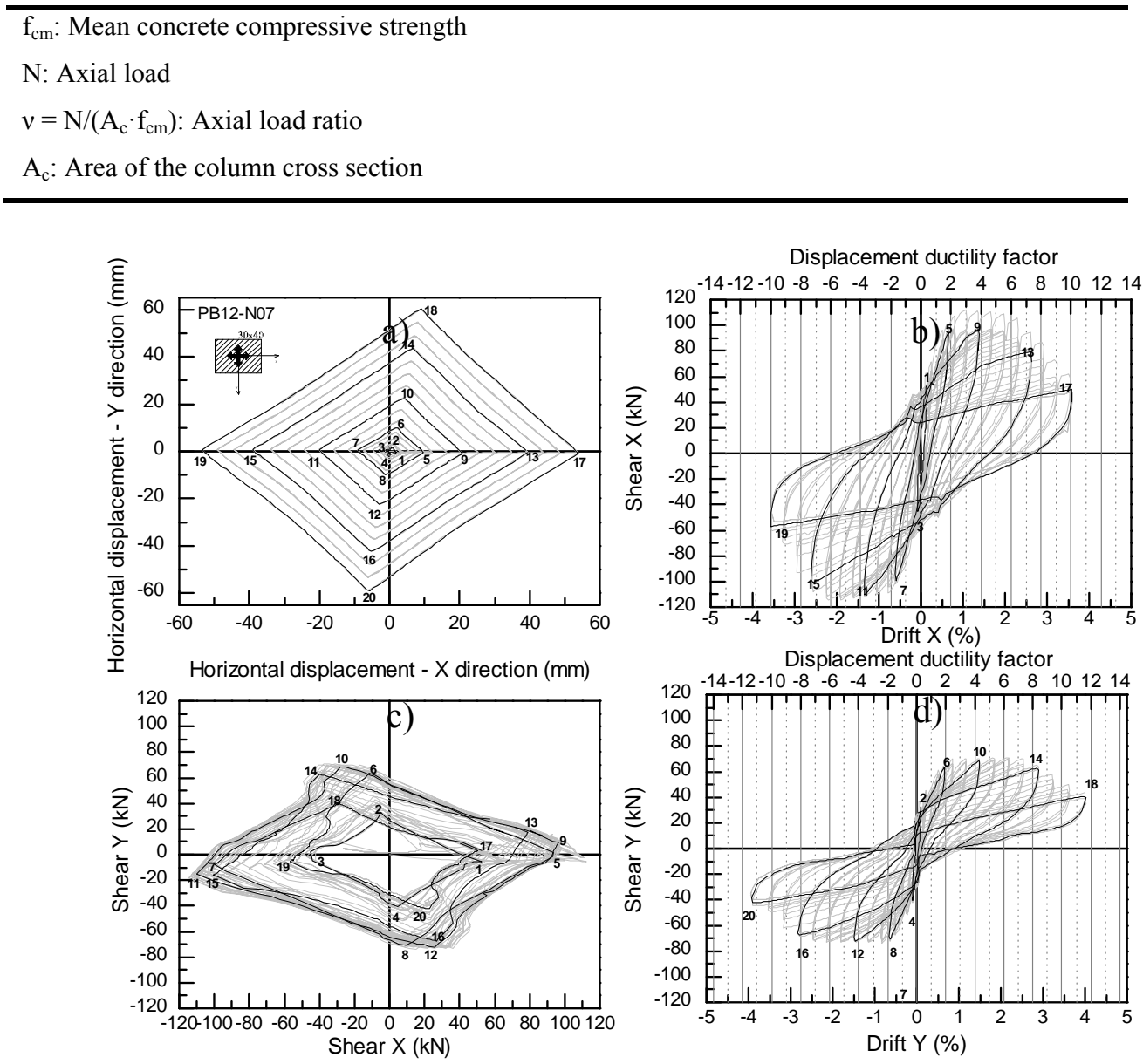

Figure 2-Global results of rectangular column PB12-N07 for rhombus load path

\section{BIAXIAL DAMAGE INDEX}

The structural damage induced by earthquakes can be quantified in order to assess the structure relative to a pre-defined set of limit states [12].

Damage indices (DIs) are generally divided into two categories: local and global. Local indices are calibrated for a specific structural member. Global indices, on the other hand, are used to predict the failure of a complete structure, and are usually computed as a weighted combination of local damage indices of individual members [13].

A good damage assessment method should have general applicability, i.e., it should be valid for a variety of structural systems; it should be based on a simple formulation, be easy to use and generate easily interpretable results $[14,15]$.

Damage indices can be classified as cumulative or noncumulative. Noncumulative indices relate the state of damage to peak response quantities and do not account for cyclic loading effects. Cumulative indices include part or all of the loading history to predict the capacity reduction due to cyclic repetitive loading [13]. Different authors have performed extensive reviews of the DIs proposed in the literature [16-19].

The formulation used in this study for the damage index estimation is based on the methodology proposed by Park \& Ang [9]. In the following section, this index and the corresponding results for the columns tested uniaxially are presented. Also, different combinations of the original Park \& Ang methodology are adopted and applied to columns tested biaxially. 


\subsection{Original Park \& Ang damage index}

The damage index (DI) proposed by Park \& Ang $[8,9]$ is defined by a linear combination of the normalized maximum deformation and the normalized dissipated hysteretic energy resulting from cyclic loading. The Park \& Ang DI is therefore expressed by:

$$
D I=\frac{d_{\max }}{d_{u}}+\beta \frac{\int d E}{F_{y} \cdot d_{u}}
$$

where $d_{\max }$ is the maximum displacement of the structural member, $d_{u}$ is the ultimate curvature displacement, $\int \mathrm{dE}$ is the dissipated hysteretic energy and $\mathrm{F}_{\mathrm{y}}$ is the yielding strength of the structural member; $\beta$ is a degradation parameter which represents the influence of cyclic response on column damage and can be estimated with empirical expressions based on structural parameters. The damage index typically ranges from 0 to 1 , although the unitary upper bound is just a conventional threshold based on the assumption that total damage (failure) is reached when DI $\geq 1$.

Several empirical expressions based on experimental results can be found in the literature to estimate the strength degradation parameter $(\beta)$. A typical value of 0.05 is often adopted [20]. Expression (2) was proposed by Kunnath et al. [21] and is one of the most used expressions to estimate the parameter $\beta$.

$$
\beta=0.9^{100 e \rho_{w}}\left(0.37 \max \{v ; 0.05\}+0.5 .\left(\omega_{t}-0.17\right)^{2}\right)
$$

where $\rho_{\mathrm{w}}$ is the volumetric confinement ratio (volume of closed stirrups divided by the volume of confined concrete core), $v$ is the normalized axial stress (taken as positive for compression), and $\omega_{\mathrm{t}}$ is the mechanical ratio of tensile longitudinal reinforcement.

Concerning the ultimate deformation capacity, some expressions have been proposed based on experimental tests performed up to failure on beams and columns. Park et al. [8] suggested expression (3) to estimate the ultimate displacement. According to the study performed by Fardis et al. [19], it was concluded that this equation leads to the best agreement of the Park \& Ang index with several experimental results analyzed.

$$
\begin{gathered}
R_{u}(\%)=1.958 t\left(\frac{l}{d}\right)^{0.93} \cdot \rho^{-0.27} \cdot \rho_{w}^{0.48} \cdot v^{-0.48} \cdot f_{c}^{-0.15} \\
R_{u}(\%)=\frac{\delta_{u}}{l} ; \rho=\rho_{l} \cdot \frac{f_{y}}{f_{c}} ; v=\frac{N}{b \cdot d \cdot f_{c}}
\end{gathered}
$$

$R_{u}(\%)$ is the ultimate rotational capacity (in percentage); $\delta_{u}$ is the ultimate horizontal displacement capacity; $\frac{l}{d}$ is the shear span ratio; $\rho$ is the normalized steel ratio; $\rho_{l}$ is the volumetric ratio of longitudinal steel; $\rho_{w}$ is the confinement ratio (in percentage and taken as $0.4 \%$ if $\rho_{w}<0.4 \%$ ); $v$ is the normalized axial stress (taken as 0.05 if $v<0.05$ ); $\mathrm{N}$ is the axial load (in $\mathrm{kN}$ ); $\mathrm{b}$ is the cross-section width; $\mathrm{d}$ is the effective depth of the cross-section; $f_{c}$ is the concrete strength (in $\mathrm{kPa}$ ); and $f_{y}$ is the yielding strength of steel reinforcement (in $\mathrm{kPa}$ ).

In order to establish a correspondence between the calculated DI values and the experimentally observed damage, Table 2 presents the DI ranges for each damage degree, based on post-earthquake damage reports [14]. 
Table 2 - Calculated damage index vs. observed damage

\begin{tabular}{|c|c|c|}
\hline \multicolumn{2}{|r|}{ Damage inspection } & \multirow{2}{*}{$\begin{array}{l}\text { Calculated local } \\
\text { damage index }\end{array}$} \\
\hline Degree of damage & Physical appearance & \\
\hline Collapse & Total or partial building collapse & $>1.00$ \\
\hline Severe & $\begin{array}{l}\text { Extensive crushing of concrete; disclosure of buck- } \\
\text { led reinforcements }\end{array}$ & $0.75-1.00$ \\
\hline Moderate & $\begin{array}{l}\text { Extensive large cracks; spalling of concrete in } \\
\text { weaker elements }\end{array}$ & $0.35-0.75$ \\
\hline Minor & $\begin{array}{l}\text { Minor cracks throughout building; partial crushing } \\
\text { of concrete columns }\end{array}$ & $0.10-0.35$ \\
\hline Slight & Sporadic occurrence of cracking & $0.00-0.10$ \\
\hline
\end{tabular}

\subsection{Application of the Park \& Ang damage index to the uniaxial test results}

The Park \& Ang DI was computed from the uniaxial test results using expressions (2) and (3) to estimate $\beta$ and the ultimate displacement $d_{u}$, respectively, for each direction of RC columns. The obtained results (for each direction) are summarized in Table 3.

Table 3 - Estimated parameters for RC column damage index calculations

\begin{tabular}{ccccc}
\hline Column & $\begin{array}{c}\text { Geometry } \\
{[\mathrm{cm} \times \mathrm{cm}]}\end{array}$ & direction & $\beta$ & $\delta_{u}(\mathrm{~mm})$ \\
\hline PB01-N01 & $20 \times 40$ & Strong (X) & 0.038 & 92.94 \\
PB01-N05 & $30 \times 40$ & Strong (X) & 0.047 & 80.22 \\
PB02-N06 & $30 \times 40$ & Weak (Y) & 0.033 & 142.44 \\
PB01-N09 & $30 \times 50 x$ & Strong (X) & 0.038 & 73.46 \\
PB02-N010 & $30 \times 50$ & Weak (Y) & 0.038 & 120.56 \\
PB01-N13 & $30 \times 30$ & Strong (X) & 0.043 & 108.84 \\
\hline
\end{tabular}

The results are plotted in Figure 3 in terms of DI evolution during the cyclic tests. For each DI curve, the drift value corresponding to each damage state observed during the tests is plotted with a specific marker, which can be compared with the ranges of damage degree described in the previous section.

Based on the results obtained in terms of DI evolution (and associated damage description) for the six columns uniaxially tested, it can be concluded that good agreement is found between DI quantification and the physical damage observed in the tested columns. 


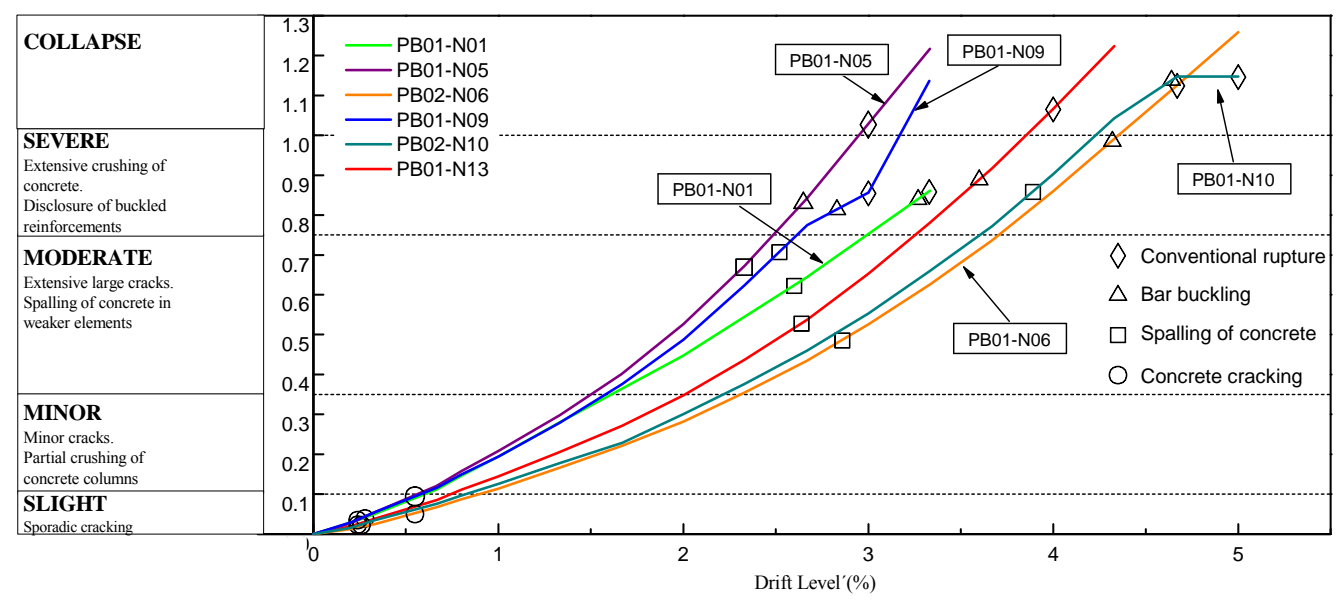

Figure 3 - Damage index evolution for uniaxial tests

\subsection{Damage index for RC columns under biaxial loading conditions}

As discussed previously, RC elements biaxially loaded go through given damage states for earlier levels of drift demand when compared with uniaxially loaded elements. Since the damage indices for RC elements available in the literature (such as the Park \& Ang index, for example) were mainly developed and calibrated for elements under uniaxial loading conditions, this study focused on the adequacy of recent proposals of DI formulations for columns under biaxial loading, including also new formulations proposed by the authors of this paper.

All these proposals are based on the philosophy of the original Park \& Ang DI model, i.e. the combination of one component for the maximum deformation demand with another for the dissipated energy. The proposals are validated against test results of columns biaxially loaded and their accuracy is discussed concerning the representativeness of damage evolution of RC elements under biaxial loading.

Expressions 7 to 10 for the evaluation of the $\mathrm{DI}$ of $\mathrm{RC}$ columns under biaxial loading $\left(\mathrm{DI}_{\mathrm{bi}-}\right.$ axial) were previously studied by Qiu et al. [22]. Thus, the present study focus on the assessment and comparison the DIs given by those expressions as well as by three other expressions (11) to (13) herein proposed. In all these expressions, $\mathrm{DI}_{\text {biaxial }}$ is the biaxial damage index, $\mathrm{DI}_{\mathrm{x}}$ and $\mathrm{DI}_{\mathrm{y}}$ refer to the damage indices calculated for each independent direction, $\mathrm{E}_{\mathrm{x}}$ and $\mathrm{E}_{\mathrm{y}}$ are the cumulative dissipated energy calculated for each independent direction, and $\lambda$ is a constant parameter experimentally calibrated.

Note that in expression (13), the $\mathrm{DI}_{\text {biaxial }}$ value is based on the calculation of the resultant displacements and total energy, rather than the sum of DIs for each direction. Thus, for each step the maximum resultant displacement $\left(\mathrm{d}_{\text {max,res }}\right)$ is calculated and, for this resultant direction, the ultimate displacement $\left(\mathrm{d}_{\mathrm{u}, \mathrm{res}}\right)$ and the equivalent resultant yielding force $\left(\mathrm{F}_{\mathrm{y}, \mathrm{res})}\right.$ are estimated. For each step, the total energy is simply calculated as the sum of the dissipated energy associated with each direction.

The $d_{u, \text { res }}$ and $F_{y}$,res values (for each analysis) are calculated for the loading direction $(\alpha)$, based on a resultant interaction curve with an assumed shape. Four different shape types were tested for this curve, namely one linear, two elliptical and one parabolic, as depicted in Figure 4. From the four curves studied, the strategy based on the parabolic one gives the best results, and so this surface was adopted for the comparisons developed in the next section.

$$
D I_{\text {biaxial }}=D I_{x}+D I_{y}-\lambda \cdot \min \left(D I_{x}, D I_{y}\right)
$$




$$
\begin{gathered}
D I_{\text {biaxial }}=\max \left(D I_{x}, D I_{y}\right)+\frac{E_{x} \text { or } E_{y}}{E_{x}+E_{y}} \cdot \min \left(D I_{x}, D I_{y}\right) \\
D I_{\text {biaxial }}=\max \left(D I_{x}, D I_{y}\right)+\frac{D I_{x} \text { or } D I_{y}}{D I_{x}+D I_{y}} \cdot \min \left(D I_{x}, D I_{y}\right) \\
D I_{\text {biaxial }}=\left\{\begin{array}{c}
\frac{d_{\max , x}}{d_{u, x}}+\beta \frac{E_{x}+E_{y}}{F_{y, x_{x} \cdot d_{u, x}}} \quad\left(d_{\max , x}>d_{\text {max }, y}\right) \\
\frac{d_{\text {max }, y}}{d_{u, y}}+\beta \frac{E_{x}+E_{y}}{F_{y, y} \cdot d_{u, y}} \quad\left(d_{\text {max }, y}>d_{\text {max }, x}\right.
\end{array}\right. \\
D I_{\text {biaxial }}=D I_{x}+D I_{y} \\
D I_{\text {biaxial }}=\sqrt{D I_{x}{ }^{2}+D I_{y}{ }^{2}} \\
D I_{\text {biaxial }}=\frac{d_{\text {max }, \text { res }}}{d_{u, \text { res }}}+\beta \frac{E_{x}+E_{y}}{F_{y, r e s} \cdot d_{u, \text { res }}}
\end{gathered}
$$

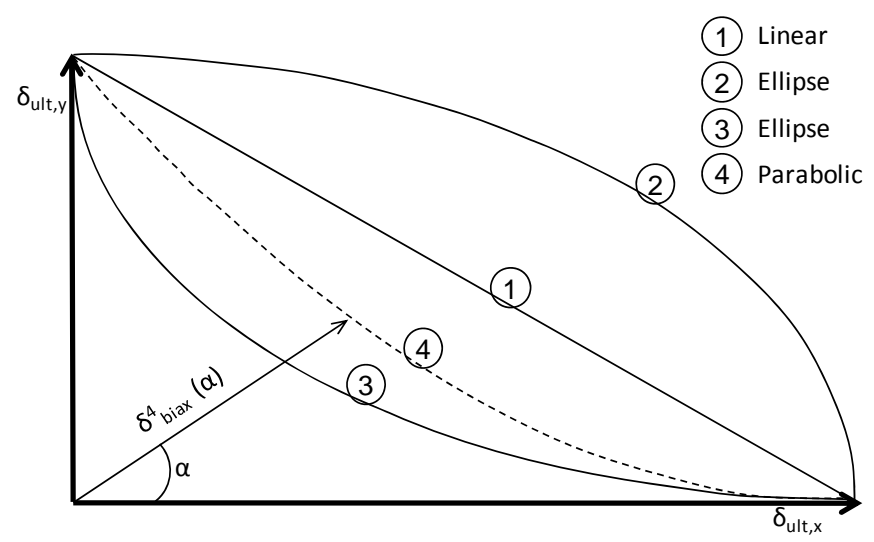

Figure 4 - Interaction curves assumed for the evaluation of the ultimate resultant displacement and equivalent yielding force

\subsection{Analysis of the obtained results}

The accuracy of each expression presented in the previous section for the estimation of damage in RC columns under biaxial loading conditions is evaluated based on a scoring procedure. For each of the four damage states defined based on visual inspection, the DIs calculated by each expression are assessed by assigning a given score. Thus, if the DI calculated (with a certain expression for each damage state) yields a value within the range presented in Table 4, then it is assigned a score of one; otherwise it is assigned zero. Therefore, for each column the score may vary between 0 and 4 . Based on the results of the work carried out by Park et al. [8], where DIs' boundaries for each damage degree observed after earthquake events were adapted to the observed damage states as reported in previous sections, Table 4 includes proposals of DI ranges for each damage state. 
Table 4 - Damage index ranges for each damage state adopted in the scoring procedure

\begin{tabular}{lc}
\hline Damage state & DI range \\
\hline Conventional rupture & $>0.80$ \\
Reinforcing steel bar buckling & $0.55-0.80$ \\
Concrete spalling & $0.30-0.70$ \\
Cracking & $0.00-0.10$ \\
\hline
\end{tabular}

The DI was computed for each biaxial test using expressions (7) to (13), whilst expressions (2) and (3) were adopted to estimate the parameter $\beta$ and the ultimate displacement (for each RC column direction). The corresponding results are summarized in Table 5.

Table 5 - Estimated parameters for the damage index calculations

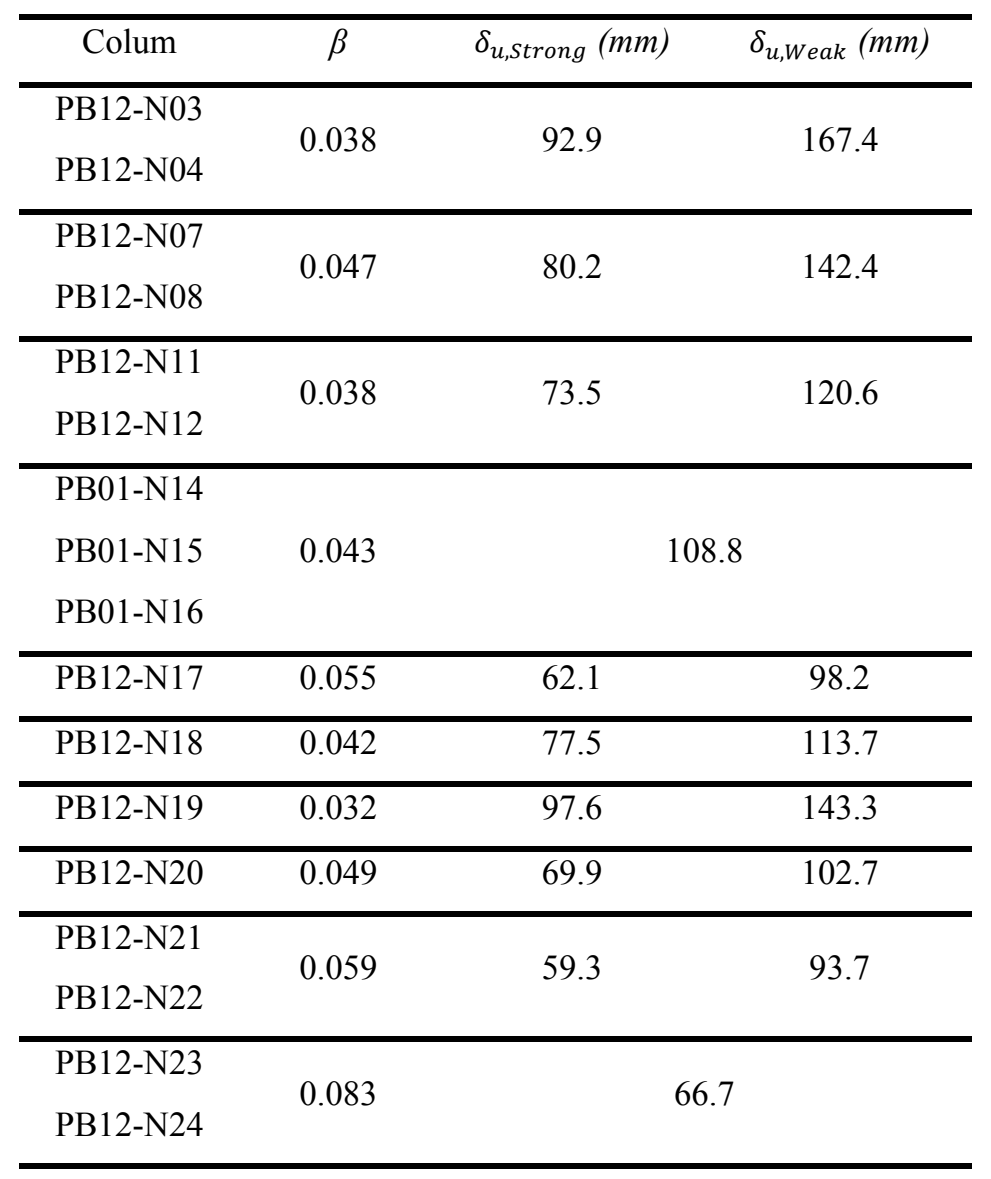

For the DI calculations using expression (7), the parameter $\lambda$ proposed by Qiu et al. [22] is taken equal to 0.5 . However, for the experimental results analyzed in this work, the option by $\lambda=0.85$ was seen to provide the highest score.

As for the proposal presented in expression (13), the best results are obtained using the parabolic curve, given by expressions (14) and (15), which depend on the parameter P. By comparing the obtained DI results with the experimental observation, the value $\mathrm{P}=-1.8$ was found to yield the best score. 


$$
y=K+\frac{1}{4 P} *(x-H)^{2}
$$

where

$$
K=\frac{1}{4}\left(4 * \delta_{u l t, y}-\frac{\left(\delta_{u l t, x}^{2}+4 \cdot \delta_{u l t, y} \cdot P\right)^{2}}{4 \cdot \delta_{u l t, x}^{2} \cdot P}\right), \text { and } H=\frac{1}{4}\left(\frac{\delta_{u l t, x}^{2}+4 \cdot \delta_{u l t, y} \cdot P}{2 \cdot \delta_{u l t, x}}\right)
$$

The DIs estimated using the different expressions are summarized in Table 6, where the adequacy of each expression in representing the damage evolution is finally assessed, summing up the scores for each of the fifteen columns studied.

Table 6 - Scores obtained for each column with the different biaxial DI expressions

\begin{tabular}{cccccccc}
\hline Column & $(7)$ & $(8)$ & $(9)$ & $(10)$ & $(11)$ & $(12)$ & $(13)$ \\
\hline PB12-N07 & 4 & 4 & 4 & 2 & 3 & 4 & 2 \\
PB12-N08 & 4 & 3 & 3 & 3 & 1 & 3 & 4 \\
PB12-N11 & 3 & 4 & 4 & 2 & 3 & 4 & 2 \\
PB12-N12 & 3 & 3 & 3 & 2 & 2 & 3 & 4 \\
PB12-N14 & 3 & 1 & 1 & 2 & 1 & 2 & 3 \\
PB12-N15 & 4 & 2 & 2 & 2 & 1 & 2 & 4 \\
PB12-N16 & 4 & 4 & 4 & 4 & 2 & 4 & 4 \\
PB12-N17 & 4 & 3 & 2 & 2 & 2 & 4 & 2 \\
PB12-N18 & 3 & 3 & 3 & 3 & 4 & 3 & 2 \\
PB12-N19 & 2 & 4 & 4 & 2 & 4 & 2 & 1 \\
PB12-N20 & 3 & 2 & 2 & 2 & 1 & 2 & 4 \\
PB12-N21 & 2 & 2 & 2 & 2 & 2 & 2 & 3 \\
PB12-N22 & 3 & 2 & 2 & 3 & 1 & 2 & 2 \\
PB12-N23 & 3 & 2 & 2 & 3 & 1 & 2 & 2 \\
PB12-N24 & 2 & 1 & 1 & 1 & 1 & 1 & 3 \\
\hline Total & $\mathbf{4 7}$ & $\mathbf{4 0}$ & $\mathbf{3 9}$ & $\mathbf{3 5}$ & $\mathbf{2 9}$ & $\mathbf{4 0}$ & $\mathbf{4 2}$ \\
\hline
\end{tabular}

Table 6 shows that expressions (7) and (13) yielded the best total scores and, therefore, Figure 5 and 6 include (for each of the RC columns' biaxial tests) the evolution of the DIs calculated with expressions (7) and (13), respectively. The plots evidence the damage states observed in the tests (cracking, concrete spalling, bar buckling and conventional failure) and it can be seen that both expressions give DIs that agree well with the physical damage evolution observed in the columns during the cyclic tests. 


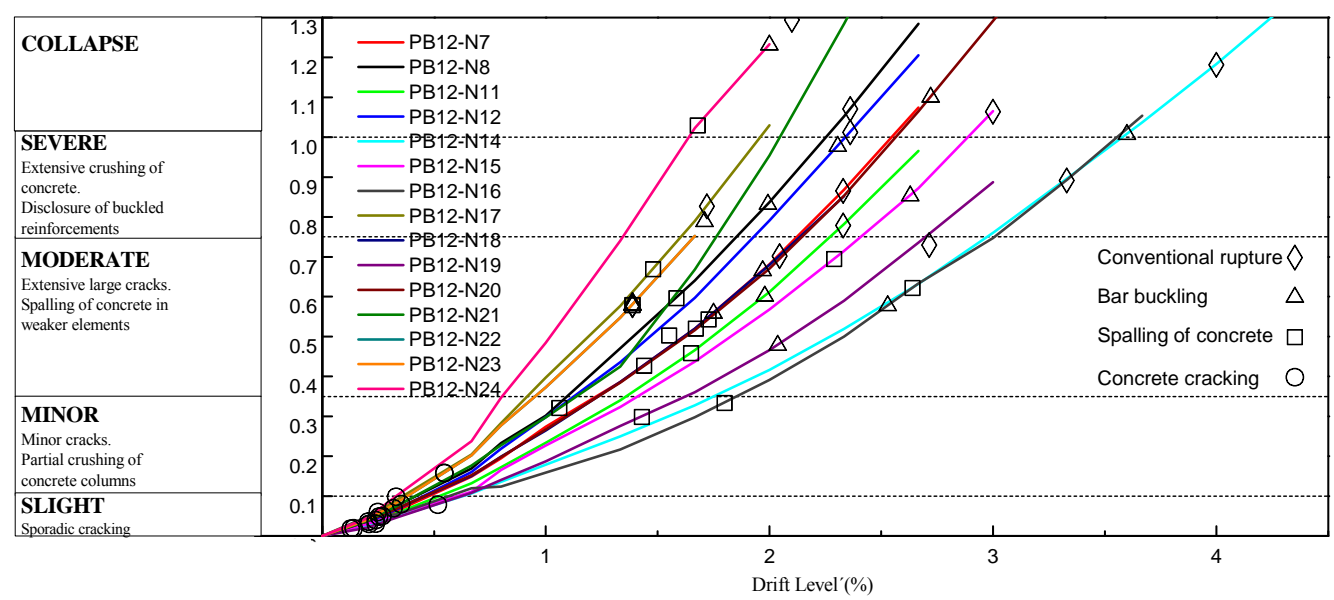

Figure 5 - Evolutions of damage index, calculated with expression (7), for each biaxial test

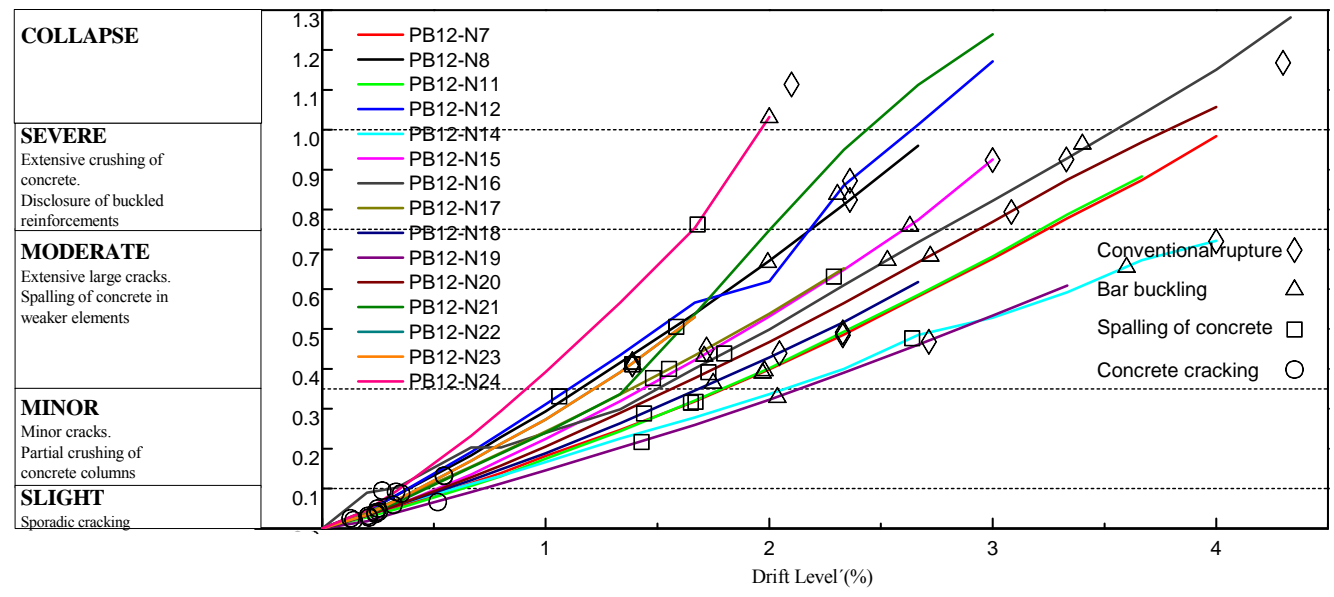

Figure 6 - Evolutions of damage index, calculated with expression (13), for each biaxial test

\section{CONCLUSIONS}

Even though it is recognized that $\mathrm{RC}$ elements under biaxial earthquake loading can experience higher levels of damage than elements under uniaxial loading conditions, the quantification of these reductions is not fully developed. This paper is therefore focused on the damage evolution in RC columns under uniaxial and biaxial horizontal loading conditions with constant axial load, further proposing new expressions for the damage quantification of columns under biaxial loading.

A large number of questions are still open concerning the biaxial behavior of $\mathrm{RC}$ columns, especially regarding the description and evaluation of the damage based on damage indices. In the present work, several expressions (based on the concepts inherent to the well known Park \& Ang uniaxial damage index) were tested and the proposal giving better results was calibrated with the columns' test results. However, these expressions need to be checked against other experimental results and especially with results of tests on building structures subjected to bidirectional loading demands. Even so, the research work reported is expected to contribute towards a better understanding of the biaxial response of RC columns. 


\section{ACKNOWLEDGMENTS}

This paper reports research developed under financial support provided by "FCT - Fundação para a Ciência e Tecnologia", Portugal, namely through the $\mathrm{PhD}$ grants of the first author with reference $\mathrm{SFRH} / \mathrm{BD} / 63032 / 2009$, and through the research project PTDC/ECM/102221/2008.

\section{REFERENCES}

[1] CEB, "RC frames under earthquake loading," Lausanne Bulletin 220, 1996.

[2] H. Takizawa, M. Aoyama, and . "Biaxial effects in modelling earthquake response of RC structures," Earthquake Engineering and Structural Dynamics, vol. V. 4, pp. 523-552, 1976.

[3] M. E. Marante and J. Flórez-López, "Model of damage for RC elements subjected to biaxial bending," Engineering Structures, vol. 24, pp. 1141-1152, 2002.

[4] T. Paulay and M. J. N. Priestley, Seismic design of RC and masonry buildings - John Wiley - ISBN 0-471-54915-0, 1992.

[5] Y. J. Park, Y. K. Wen, and A. H.-S. Ang, "Random vibration of hysteretic systems under bi-directional ground motions," Earthquake Engineering and Structural Dynamics, vol. 14, pp. 543-557, 1986.

[6] FEMA356, "Prestandard and commentary for the seismic rehabilitation of buildings," ed: Federal Emergency Management Agency, Washington (DC), 2000.

[7] SEAOC-Vision2000, "Performance based seismic engineering of buildings, vols. I and II: Conceptual framework," ed: Structural Engineers Association of California, Sacramento (CA), 1995.

[8] Y. J. Park, A. H. S. Ang, and Y. K. Wen, "Damage-limiting aseismic design of buildings," Earthquake Spectra, vol. 3, No. 1, 1987.

[9] Y. J. Park and H. S. Ang, "Seismic Damage Model for Reinforced Concrete," ASCE J Struct Eng, vol. 111(4), pp. 722-739, 1985.

[10] H. Rodrigues, A. Arêde, H. Varum, and A. G. Costa, "Experimental study on the biaxial bending cyclic behaviour of RC columns," presented at the 14th European Conference on Earthquake Engineering Ohrid, Republic of Macedonia, 2010.

[11] H. Rodrigues, H. Varum, A. Arêde, and A. Costa, "A comparative analysis of energy dissipation and equivalent viscous damping of RC columns subjected to uniaxial and biaxial loading," Engineering Structures, vol. 35, pp. 149-164, 2012.

[12] A. Arêde, "Seismic assessment of reinforced concrete frame structures with a new flexibility based element," PhD Thesis, Faculdade de Engenharia, Universidade do Porto, Porto, 1997.

[13] M. M. Hachem, S. A. Mahin, and J. P. Moehle, "Performance of Circular Reinforced Concrete Bridge Columns under Bidirectional Earthquake Loading," PEER 2003/06 UCB/ENG-9374, University of California, Berkeley, 2003.

[14] H. Varum, "Seismic assessment, strengthening and repair of existing buildings," $\mathrm{PhD}$ Thesis, Civil Engineering Department, University of Aveiro, Aveiro, 2003.

[15] J. E. Stephens and J. P. T. Yao, "Damage assessment using response measurements," ASCE Journal of Structural Engineering, vol. 113, pp. 787-801, 1987.

[16] E. Coelho, "Comportamento sísmico de estruturas em pórtico de betão armado Avaliação da resposta não-linear histerética," PhD Thesis, IST, Lisbon, 1992. 
[17] M. S. Williams and R. G. Sexsmith, "Seismic Damage Indices for Concrete Structures: A State-of-the-Art Review," Earthquake Spectra, vol. 11, pp. 319-349, 1995.

[18] Y. S. Chung, C. Meyer, and M. Shinozuka, "Seismic damage assessment of reinforced concrete members," NCEER-87-0022, National Center for Earthquake Engineering Research, Buffalo, N.Y., 1987.

[19] M. N. Fardis, S. N. Economu, A. N. Antoniou, P. J. Komodromos, and M. G. Sfakianakis, "Damage Measures and Failure Criteria - Part I," Contribuition of University of Patras, Final Report of Cooperative Research on the Seismic Response of Reinforced Concrete Structures - 2nd Phase, LNEC, Lisboa, 1993.

[20] R. Bento, "Assessment of the Seismic Behaviour of Reinforced Concrete Framed Structures: An Approach Based on Damage Indices," PhD, IST, Lisbon, 1996.

[21] S. K. Kunnath, A. M. Reinhorn, and Y. J. Park, "Analytical modelling of inelastic seismic response of RC structures," ASCE, Journal of Structural Engineering, vol. 116, No4, 1990.

[22] F. Qiu, W. Li, P. Pan, and J. Qian, "Experimental tests on RC columns under biaxial quasi-static loading," Engrg Structures, vol. Vol. 24, pp. pp. 419-428, 2002. 